\title{
Improving Undergraduate Engineering Education with Educational Module Library and Vertical Integration Projects
}

\author{
Dr. Lei Zhang, University of Maryland, Eastern Shore
}

Dr. Lei Zhang received his Ph.D. Degree in Electrical Engineering on 2011 from the University of Nevada, Las Vegas. Since 2012 he is working in the Department of Engineering and Aviation Sciences, University of Maryland Eastern Shore. His main research interests include image processing, autonomous system development, optical SoC/NoC architecture, and on-chip optoelectronic device design.

\section{Prof. Ibibia K. Dabipi, University of Maryland, Eastern Shore}

I. K. Dabipi has been in academia for approximately 26 years during which he worked for Bellcore, AT\&T Bell Labs and Southern University. He was the Chair of the Electrical Engineering Department at Southern University from 1997 to 2001. He was Professor and Chair of the Engineering and Aviation Science Department at University of Maryland Eastern Shore from 2001 - 2006. He is currently a Professor in the Department of Engineering and Aviation Sciences at University of Maryland Eastern Shore.His research interests are in the areas of Computer Security and Network Management, Parallel Computing and Algorithms Development, Performance Evaluation of Computer Networks, Optimization of Transportation Networks, and Economic Analysis of Transportation Facilities and Human factors in Aviation Security. $\mathrm{He}$ is a member of ASEE, HKN, ACM and a senior member of IEEE

\section{Dr. Yuanwei Jin, University of Maryland, Eastern Shore}

Yuanwei Jin is an Associate Professor of electrical engineering with the University of Maryland Eastern Shore. He received a Ph.D. degree in electrical and computer engineering from the University of California at Davis in 2003. His research interests are in the general area of statistical signal and image processing, with applications in radar/sonar, biomedical imaging, inverse problems, structural health monitoring, and wireless communications. He holds two US patents and has published more than seventy journal and conference papers. He received a 2010 Air Force Summer Faculty Fellowship award. He was a recipient of an Earle C. Anthony Fellowship from the University of California at Davis. He is a Senior Member of the IEEE.

Dr. Payam Matin, University of Maryland, Eastern Shore

Dr. Payam Matin is currently an Associate Professor in the Department of Engineering and Aviation Sciences at the University of Maryland Eastern Shore (UMES), Princess Anne, Maryland. Dr. Matin has received his Ph.D. in Mechanical Engineering from Oakland University, Rochester, Michigan in May 2005. He has taught a number of courses in the areas of mechanical engineering and aerospace at UMES. He has served as departmental ABET committee chair through a successful accreditation visit in Fall 2012. Dr. Matin's research has been mostly in the areas of Computational Mechanics and Experimental Mechanics with applications in Solid Mechanics, Plasticity and Sheet Metal Forming. Dr. Matin has published more than 25 peer-reviewed journal and conference papers. Dr. Matin is the recipient of NSF MRI award as a Co-PI. Dr. Matin worked in Automotive industry for Chrysler Corporation from 2005 to 2007. He Joined UMES in August 2007. He is affiliated with ASME and ASEE professional societies 


\title{
Improving Undergraduate Engineering Education with Educational Module Library and Vertical Integration Projects
}

\author{
Lei Zhang, Ibibia Dabipi, Yuanwei Jin, Payam Matin \\ Dept. of Engineering and Aviation Sciences, University of Maryland Eastern Shore
}

\begin{abstract}
In this paper, we present our experience on improving undergraduate engineering education with two Experiential Learning approaches. The first is Educational Module Library (EML) and the second is Vertical Integration Project (VIP). The EML is a collection of typical engineering modules with diversified functions. All modules in the EML are carefully developed by students with latest technologies under the guidance of faculty. The EML is featured in simple, popular, complete and user-friendly. The EML can significantly lower down the difficulty for students in launching a new project and provide strong support during the whole implementation process. In parallel, the second approach VIP offers students at different levels a great opportunity to work together on building advanced systems. Through VIP programs, students can continuously get involved in engineering practice, receive training on diversified skills and develop interests, motivation and concentration. In addition, an adopted mobile laboratory tool, Analog Discovery (AD) kit has greatly facilitated the implementation of these two approaches.
\end{abstract}

\section{Keywords}

Experiential Learning, Educational Module Library, Vertical Integration Project, Analog Discovery Kit

\section{Introduction}

\subsection{Overview}

The key of successful engineering education is to continuously expose students to the latest technology, provide them opportunities to practice, and involve them in innovative projects. The Experiential Learning Theory (ELT) unveils the central role of experience plays in the learning process [1-3], as shown in Kolb's cycle of experiential learning model in Fig. 1. And many researches have shown how students' active involvement and engagement in practical work can greatly improve their knowledge acquisition and general cognitive development [4-6].

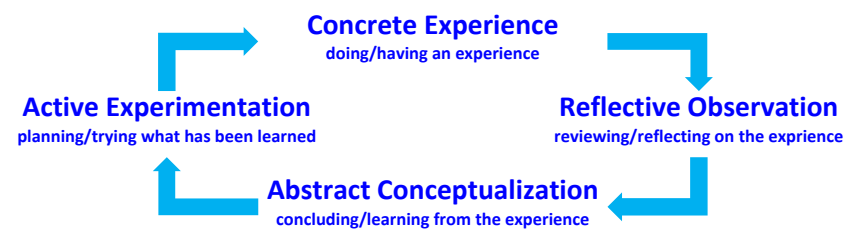

Fig. 1. Kolb's cycle of experiential learning [7].

However, practically there are many obstacles in applying Experiential Learning methods. The first problem comes from the limitation of students' knowledge and experience, as wells as the 
availability of accessible information and resources. Students find brilliant ideas from time to time, but there is a huge gap between what they can imagine and what they can implement. On the market millions of components are accessible for students to build projects, but they can get in touch with only a few of them in class. Shortly, students need guidelines and kits to practice, and they need templates, modules and clear instructions to realize their imagination quickly and easily.

In responding to this need, first we initialize the development of a comprehensive project components collection, denoted as the Educational Module Library (EML). Basically, EML is a diversified collection of components and devices such as sensors, motors and microprocessors that can be used as basic elements for students to build engineering projects. The purpose of EML is to provide standardized modules to cover most needs for students in experiential learning through engineering practice. The EML majorly is developed by students under the guidance of faculty members. For the time being new modules are to be added, and old modules will be updated or replaced.

Besides the hardware provided by the EML, students also need training to acquire experiences in engineering practice. Correspondingly, we create a mechanism for students to work together, as so called the Vertical Integration Projects (VIP). VIP offers advanced projects particularly defined by faculty members, for students in different backgrounds, levels and expertise to team-working, collaborate and develop. For the time being, when senior students in the team graduate, projects will refined The VIP concept that has been widely practiced, for instance in [8]. Nevertheless, in our VIP experience, the development of EML can greatly facilitate the implantation of the Vertical Integration Projects (VIP) program, and vice versa.

To successfully implement those approaches, a mobile laboratory device 'Analog Discovery' (AD) kit is adopted. The AD kit is a portable and low-cost multifunctional instrument that can measure, record and generate analog and digital signals. In the past, one major obstacle to students' engineering practice was the availability of limited laboratory resources. By the use of the kit, students can test components, conduct experiments, and work on projects on their own flexible time and even outside of campus laboratories.

\subsection{Paper Organization}

In the following, Sect. 2 introduce the EML we are developing and provide more details. Sect. 3 shows how the educational module library will greatly improve the implementation of our vertical integrated projects. Sect.4 presents how EML and VIP significantly strengthen the education process. And finally Sect.5 concludes our whole work.

\section{Educational Module Library}

\subsection{EML Overview}

The main purpose of the Education Module Library (EML) is to enhance students' engagement, improving their STEM learning and practicing experience. More specifically, lower down the threshold and provide students an easy yet professional way to build advanced engineering projects.

Most of the modulated components in EML can be found in any electronic online store. However, EML can offer a standardized and efficient way for students to access and utilize them, by mainly standing on the following features. 
- Simplicity.

Core component of every modules in EML is carefully selected by faculty members with atomic functions and basic requirements. Most modules are to be developed by students. These will ensure all modules are associated with engineering curriculum knowledge and won't go above students' capability.

- Completeness.

The development of every module is required to meet the standard in providing correct, detailed and complete information, including all original information from manufacturer, specs, wiring diagram, source code, hardware configuration, etc.

- Seamless.

Different to the general information offered by the manufacturer of a component, the corresponding EML provides clear and detailed information of how to connect and operate it with the specific platform.

- Referential Project Information

Besides the basic information of the module, complete information of projects that utilize the module can also be found in the EML. This provides students a comprehensive referential resource and a systematic view of the module.

Currently, there are four specializations in our engineering department, including Electrical Engineering, Mechanical Engineering, Computer Engineering and Aerospace Engineering. Practically, the inventory of EML is managed by the lab director. Students from all specialization can access the EML database, and request an item collection to build brilliant engineering projects. Every faculty in the department can evaluate students' application and approve their access to each specific item.

\subsection{Module Catagories}

The development of EML is a continuous process. New modules are added while old ones are updated or archived for the time being, endlessly. So far many modules have been added into the EML directory and more are under development. Basically, there modules can be classified into the following categories.

\subsubsection{Computing Modules}

Nowadays, a microprocessor or microcomputer is the fundamental component required to build any advanced engineering project. In our EML different microprocessors are adopted for various computing requirements.

The first is Arduino [9], an open-source microcontroller kits for building digital devices and interactive objects that can sense and control objects in the physical world. It is an entry-level microprocessor board with probably the most widely popularity. Detailed connection diagram and even source code for Arduino can be found on every online electronic store for most applicable component. Furthermore, innumerous Arduino based projects have been developed and published or posted by college, high school or even middle school students [10]. The EML included modules 
of various Arduino microprocessor boards, a series of A-Z tutorials, and a couple of typical Arduino projects span from weather station to UAV.

However, together with simplicity of Arduino is its limitation on computation capability. It can hardly support advanced computation intensive algorithms, nor image or video processing related projects. Hence a more powerful platform, Raspberry Pi [11] is adopted and corresponding modules are developed and integrated into EML. The Raspberry Pi is a low cost, credit-card sized, fully functional, general purpose ARM computer runs Linux. It is a powerful device that amazingly enables sophisticated projects with advanced functions. For example, most image or video involved modules in EML are Raspberry Pi based.

In addition, other microprocessors and single board computers modules are also adopted in EML, including the Intel Edison [12] and TI LaunchPad [13], for developing special interests projects such as wearable devices and IoT systems.

\subsubsection{EML Modules}

The majority of EML are functional modules, which basically can be classified as the following categories: 1) Sensors, including basic sensors such as thermal sensor, rotary sensor, humidity sensors, motion sensors, accelerometers, etc., and also advance sensors like GPS, dissolved oxygen, $\mathrm{pH}$, and nitrate levels sensors; 2) Motors, step motors and servos; 3) Human machine interfaces, including cameras, LCD display, touchscreen, SD card shield, etc.; 4) Communication devices, to support various protocols such as RS485, Bluetooth, XBee, Wi-Fi; and 5) Others specific modules, such as robotic arm PhantomX Pincher, and VR glasses Oculus [14].

\subsubsection{Measurement Devices}

The measurement devices played a critical role in the EML. Undoubtedly, any advanced engineering project development will involve measurement, testing, analysis processes. However, during project implementation, engineering students always suffer from the accessibility and availability of laboratory facilities offered by the department. In dealing with this issue, a mobile laboratory kit 'Analog Discovery' (AD) kit is integrated into EML and offered to all students. Fig. 2 shows the AD kit, its pin-out, and the software interface [15].
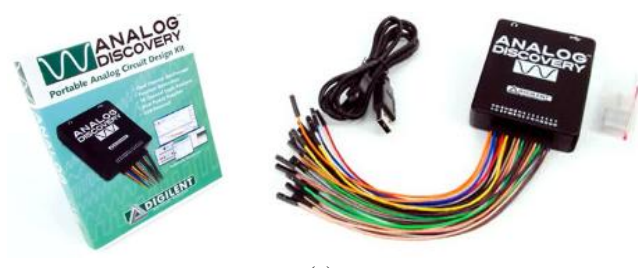

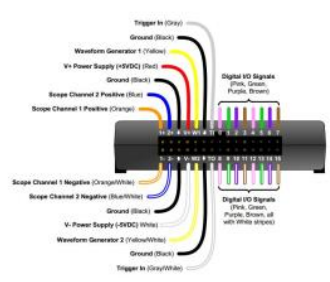

(b)

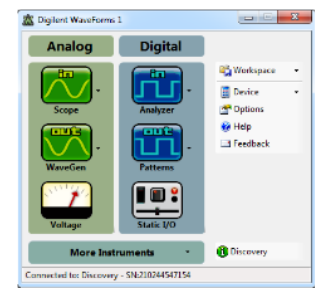

(c) 
Fig. 2. a) Analog Discovery kit, b) pin-out, and c) interface of 'Waveform'.

The AD kit is a small $\left(3.2^{\prime \prime} \times 2.6^{\prime \prime} \times 0.8^{\prime \prime}\right)$, portable and low-cost ( $\$ 99$ for US student) multifunction instrument that can measure, record and generate analog and digital signals. Driven by a free PC software 'Waveforms', the AD kit can be configured to work as all major laboratory instruments including multi-meter, function generator, DC power supply and oscilloscope. In short, the AD kit can drive, measure, and visualize, for both analog and digital signals. It brings students the convenience for testing and measurement, and also expanded the way they perceive, analyze and understand the engineering world. For the time being, they are more used to explore new stuff with the mobile kit, as the extension of their fingers and eyes.

\subsubsection{Special Interests Modules}

Besides the basic functional modules, new devices are adopted into student projects from time to time. Some of them are also identified and developed into special modules to add into the EML. For example, currently an advanced gesture control module based on MYO [16], and a virtual reality module with Oculus [14] are under development.

\subsection{Module Development}

There are several different ways that EML modules can be developed.

\subsubsection{Course Project}

In many engineering classes, open-ended problems will be assigned to student as course projects. Some outstanding solutions will be identified and refined to typical module and added into the EML.

\subsubsection{Personal Interest Project}

In the engineering department, students are always strongly encouraged to develop projects with their personal interests. This kind of projects can significantly improve students' engagement, and hence strongly supported by the department with faculty members. These projects always generate high quality modules as byproducts. Fig. 3 illustrate a design project, exoskeleton 'B.T. Suit', developed by a junior student [17]. The kit integrated diversified EML modules such as servos, cameras, microcomputer, various sensors and etc.

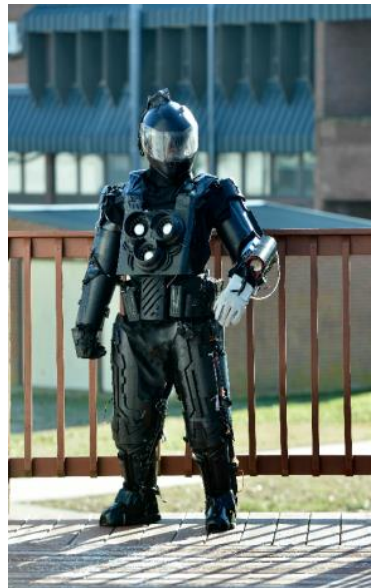

(a)

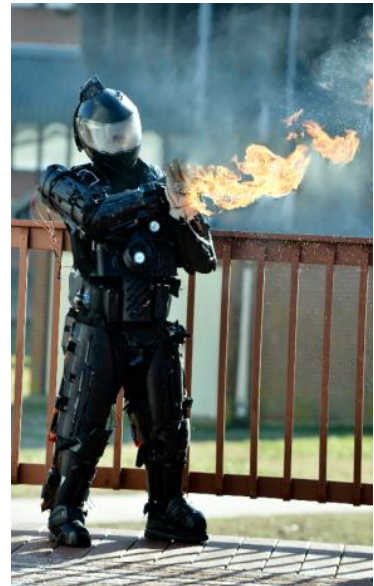

(b)

Fig. 3. a) The project suit, and b) demonstration of fire thrower. 
On the other hand, during the implementation of the project, a couple of new modules are developed for the EML. For instance, the 'Magic Glove' module which is a finger input module built with Flex sensors that can communicate to microprocessors directly or wirelessly. In another advanced human-machine interface module, the gesture control device MYO mentioned is used to generate control commands to the Raspberry Pi.

\subsubsection{Senior Design Project}

Senior design project is one of the major sources of most advanced modules. Similarly, in the engineering department, students are strongly recommended to create senior design project based on their personal interest. And the instructor will evaluate their proposals and provide guidance of the project implementation. This principle ensured students' motivation and engagement during the whole process of senior design project. On the other hand, with the instructor's approval, students are eligible to carry out their previous personal project into senior design project. For example, the 'B.T. Suit' project later is converted the senior project. A developer team is organized to work on the project to integrate more functions and meet higher requirements.

Another example is a senior design project that produces a software module. In the project student teams developed a mobile educational social network app called 'UMES Chat'. Essential development processes of the project are extracted and refined to a standard iOS based cellphone app development module and added into EML.

\subsubsection{OthersWays}

There are also many other ways of developing modules to enrich the EML. For example, a few faculty members in the department are working on robotics research projects, which have generated quite many widely useful modules. On the other hand, faculty members can identify special functions or technologies for academic purposes, and organize student team to corresponding modules development. Sect.4.1 will provide more related information.

Practically, adding a module to EML needs the endorsement from at least one faculty member who will be responsible for supporting students using the module in the future.

\subsection{Supporting the EML Development}

The development of EML is strongly supported by the department with all faculty members from many different sources. For example, course projects and senior design projects receive continuous departmental support every semester. In addition, from this year the department receives LockheedMartin grant. Partial grants will be spent on supporting senior design projects from which the EML will benefit as well.

Moreover, engineering students in the department are always strongly encouraged to propose engineering projects based on personal and academic interests. Qualified projects approved by faculty members will receive departmental support on components and tools. If the function, module or project is identified to meet the needs and standards of EML, student developers are eligible to apply for hourly-based stipend to support the development process.

\section{Vertical Integration Project with EML Support}

The vertical integration project is not a new idea but with many successful programs [8]. 
Nevertheless, our experience has unveiled how the EML can facilitate and improve the implementation of the VIP, and furtherly enhance students' inspiration, motivation and confidence.

When an ambitious student decides to launch an advanced project, he or she will be confronting several tough questions right away. First is the availability and accessibility of solutions they are seeking. Students may easily get confused with unavailable technologies beyond their capability. Even after they get on the right track, without enough practice, it is still very challenging to identify proper devices and learn how to utilize. Fortunately, precedent students have settled their experience and knowledge into modules that will pave and enlight the way for followers to advance. By searching through the EML later developers can easily to find useful pieces and design appraoches for building their projects.

The second is the team organization. People nowadays can hardly have a comprehensive knowledge collection of many fields. The capability and productivity of one developer is awlays quite limited. Consequencely, to efficiently create a new function into the system, an convenient way is to recruit an expert of the funtion to work on it. However, how to effectvely identify right team members to organize a capable team?

Interestingly, EML offers an simple solution for this issue, similar to the process how Boy Scouts kids collect badages. A certification mechanism associated with EML is under development, to keep records of all students who have accessed the EML. Positively or passively, every student will be exposed and get involved with EML modules from classes or off-class projects. Based on the project level, student's participation and pefromance, faculty memebers will evaluate his/her skill level and confer a specific module title on the student, such as 'Apprentice of Servo', 'Expert of RTK GPS', Master of Raspberry Pi', etc. Consequently, the EML based cerificate system provides a convenivent way for a student to organize a copmetitive team in adventuring the exciting engineering world. The process is quite fun, just like in how a player in an RPG game gethers a team with magician, knight, archer, etc. to explore a new dungeon, accquire experience and skills, and level up.

In addition, a task (project) online bulletin board is to be created for posting the information of all EML related projects. Through it, students can identify interested projects to participate, while intructors, mentors and adiministrators can easily check and track the latest information of all projects. Step by step, a student can light on different branches on his/her skill tree for professional development. Meanwhile, project team leaders can obtain required student labors, and these labors will receive skill trainnings as well.

We are engeged on integrating students in different levels into engineering projects from years ago [18]. With the advancing of EML and related-subsystems, now the VIP is getting thriving with more students involved into diversified projects. In addition, the veritical integration projects can also expand horizontally. Students in other departments are also attracted to participate and share the experience. For instance, computer science students have joined our projects on developing mordern computer architectures and mobile academic social network apps, in team-working with engineering junior and senior students.

\section{Student Engagement and Learning Improvement}

\subsection{Teaching Improvement}


The EML can significantly facilitate the teaching of engineering courses and labs for instructors. Accompanying with in-class lecturing, instructors can conveniently choose related modules from EML and distribute to students as assignments or course projects to practice, and as so does laboratories. When new modules are added or updated in EML, instructors will got notified. They can easily update their teaching materials by adopting new modules.

For instance, currently, the mentioned Analog Discover Kit in EML has been adopted for Basic Analog Circuit Lab (ENGE241) and Digital Logic Circuit Lab (ENGE251) and all experiments are implemented with the kit. In Microprocessor and Microcomputer lab (ENCE456), from semester to semester, different Raspberry Pi and Arduino related modules in EML are selected and provided to students for practice.

On the other hand, EML provides a convenient method for instructors to update teach materials and adopt new technologies as well. For example, this semester an Aerospace Engineering faculty want to assign a course project on Mechatronics (ENME440) for students to develop an autonomous vehicle similar to [15]. First he checked with EML and figured out that most required components or substitutes are available. Then he acquired all related documents from EML and developed the project instruction.

In addition, when an interested new technology, product, or device is available on the market, or deployed in student projects, an instructor can request for the development of the corresponding module. With the support from department and other sources, a student or a student team will be organized on the module development, and later on add the module into EML.

\subsection{Student Engagement, Learning Improvement and Profession Development}

Student's learning experience can also be greatly improved through exploring the EML and get involved into VIPs. First, as mentioned before, the development of EML is closely associated with engineering curriculum. EML provides specific modules for students in practicing experiential learning and enhance the comprehension of course knowledge. Secondly, EML offers plentiful ready-to-use resources for students to initialize various engineering projects, which can furtherly reinforce their experiential learning processes. On the other hand, by getting involved into various VIP processes, students are engaged in learning improvement and career preparation. Through VIP, students get involved into long-term practical team projects, which provide them a significant benefit in terms of the continuity, technical depth, and disciplinary breadth involved in the project. Besides, students' communication and team-working skills will also get improved through VIP process.

\section{Conclusion and Future Work}

In this paper, we presented our attempts to improve engineering education by offering students an educational module library, which is a specifically organized collection of engineering project modules. This library will not only strengthen the teaching of engineering courses, but also greatly support students' practice on implementing advanced projects. Furthermore, the module library can significantly facilitate vertical integration projects in which engineering students at different level collaborate with each other. The VIP provides students a long-term, depth-and-breadth learning environment that can keep students engaged and improve learning and profession development.

Next, we will keep enriching the EML with new hardware/software modules. EML subsystem 
and website are under development and will be loaded online soon. We will also concentrate on expanding and deepening the VIP on all aspects, to further improve students' learning experience and outcomes.

\section{References}

[1] D. A. Kolb, Experiential learning: Experience as the source of learning and development vol. 1: Prentice-Hall Englewood Cliffs, NJ, 1984.

[2] R. Loo, "A meta-analytic examination of Kolb's learning style preferences among business majors," Journal of Education for Business, vol. 77, pp. 252-256, 2002.

[3] D. Kolb, "Experiential learning as the science of learning and development," Englewood Cliffs NPH, editor1984, 1984.

[4] A. W. Astin, What matters in college?: Four critical years revisited vol. 1: Jossey-Bass San Francisco, 1993.

[5] R. J. Light, The Harvard Assessment Seminars Second Report 1992: Explorations with Students and Faculty about Teaching, Learning, and Student Life: Harvard Graduate School of Education, 1992.

[6] R. J. Light, Making the most of college: Students speak their minds: Harvard University Press, 2004.

[7] Researcher development framework Available: http://www2.le.ac.uk/departments/gradschool/training/development-framework/print-version

[8] Vertical Integrated Projects. Available: http://www.vip.gatech.edu/

[9] Arduino. Available: https://www.arduino.cc/

[10] M. Banzi, Getting Started with arduino: " O'Reilly Media, Inc.", 2009.

[11] Raspberry Pi. Available: https://www.raspberrypi.org

[12] Intel Edison. Available: http://www.intel.com/content/www/us/en/do-it-yourself/edison.html

[13] TI LaunchPad. Available: http://www.ti.com/ww/en/launchpad/launchpad.html?DCMP=mculaunchpad\&HQS=launchpad

[14] Oculus. Available: https://www.oculus.com/

[15] Available: http://engineering.nyu.edu/mechatronics/index.html

[16] MYO. Available: https://www.myo.com/

[17] L. Zhang, I. Dabipi, Y. Jin, and P. Matin, "Inspiring undergraduate students in engineering learning, comprehending and practicing by the use of analog discovery kits," in Frontiers in Education Conference (FIE), 2015. 32614 2015. IEEE, 2015, pp. 1-4.

[18] H. Xavier Shastri Domnique, Z. Lei, N. Abhijit, D. Madhumi Mitra Ph, E. H. Christopher, T. Christopher Alan, II, et al., "Experiential Learning Framework for Design and Development of Environmental Data Acquisition System Enhances Student Learning in Undergraduate Engineering Courses," Seattle, Washington. 